\title{
Project-based learning oriented STEAM: the case of micro-bit paper-cutting lamp
}

\author{
Shih-Yun Lu ${ }^{1} \cdot$ Chih-Cheng Lo ${ }^{2}$ D . Jia-Yu Syu ${ }^{1}$
}

Accepted: 26 October 2021 / Published online: 1 December 2021

(c) The Author(s) 2021

\begin{abstract}
The main purpose of the living technology curriculum is to cultivate students' interest in learning science and technology, and further to utilize their experience of learning instructions and develop their ability to integrate interdisciplinary knowledge and skills. In recent years, as countries have begun to emphasize the concept of interdisciplinary integration in the school education, STEM (Science, Technology, Engineering, and Mathematics, STEM) focuses on cultivating interdisciplinary talents. With this, STEAM highlights the role of ART because other dimensions of STEM are expected to be effectively integrated through the cultivation of aesthetics; the purpose of this study is to design a STEAM curriculum for elementary school children and to explore the impact of STEAM education on the creativity. The content of this course is based on the PBL (Project-Based Learning) with the teaching activities combining with "Chinese Paper-cutting" and "BBC micro: bit". The teaching process is used the strategy of creative thinking instruction. The research method adopts a one-group pretest-posttest design based on a purposive sampling of 21 students from one class in an elementary school. The research tools included the records of learning feedback and the creativity assessment. The empirical findings show that the projectbased learning incorporating STEAM activity has a positive significant influence on students' development of creative recognition. Since the empirical results are constricted by the short-term STEAM course, the STEAM course with the art-oriented still benefits the STEAM education and Learning effectiveness of elementary school students. The implication of interdisciplinary interactive Lamp of Paper Carving with Micro:Bit is expected to contribute to further development of STEAM course. Since the curriculum is only last for few weeks, it is too short to affect the emotional facet of creativity. Future researches are suggested to extend the teaching period and evaluate the long-term influence of PBL STEAM on students' learning attitude.
\end{abstract}

Keywords Project-based learning · Creative thinking instruction · Paper-cutting · Micro:bit · STEAM

Chih-Cheng Lo

charleslo@gm.ncue.edu.tw

1 Department of Digital Content and Technology, National Taichung University of Education, Taichung, Taiwan

2 Department of Industrial Education and Technology, College of Technology, National Changhua University of Education, Changhua City, Taiwan 


\author{
Abbreviations \\ PBL Problem-Based Learning \\ STEM Science, Technology, Engineering and Mathematics \\ STEAM Science, Technology, Engineering, Art, Mathematics
}

\section{Introduction}

\section{Research background}

Information technology has been developed applied into education rapidly in the twenty-first century. As the diversity of information society, creativity in a knowledge economic era is the key to success. Cultivating convergent and divergent thinking is the purpose of education in all levels of schools. Schools should focus on creativity, problem-solving skills, humanities, and capability of using technology across different disciplines (Land, 2013; Ozkan et al., 2021). While the importance of STEM education is highlighted, including a teaching combination of Science, Technology, Engineering, and Math (National Research Council, 2011; Salinger \& Zuga, 2009), STEAM is derived from STEM with additional "A" to highlight the importance of the art in cross-disciplinary learning toward creativity. "A" stands for social studies, humanities, language, physical, musical, fine, and performance (Yakman, 2008). Yakman (2008) also indicated that art benefits integrate cross-disciplinary curriculums and overcome limitations of each subject.

Previous studies prove that creativity can be cultivated in a practical project. By the mean of cooperating in the group, students can solve problems, enhance a sense of aesthetic. There is also a possibility to develop cross-disciplinary social value (Benton et al., 2019; Vernon, 1989). STEAM curriculum with Project-Based Learning (Hereafter as PBL) is constructed with modern technology, science, engineering, art and mathematics and centers on the learner. Students interact with the society and participate in design by constructivist learning and context-specific of art, and then respond to the challenges and problems they encounter. In this way, students can set up their goals, research and acquire knowledge and skills (Kokotsaki et al., 2016; Song, 2020). It is more important to look into how children apply new knowledge and proceed with design thinking (Druin, 2002). STEAM education allows teachers to understand how students practice a new technology from the view of the art design; and to apply the learning process of cross-disciplinary technology projects (Kuure et al., 2010). Benton et al. (2019) pointed out that though the project-based curriculum limits students in creating ideas, it ensures the appropriateness of creativity.

There are some problems in STEM curriculum development. First, the content of the STEM curriculum is more about engineering design with the concept of steps. It is not related to aesthetics. Seconds, project-based STEM curriculum is considered mainly in secondary school or above with purpose with product engineering, not design thinking. The outcome of creative teaching is still unknown (Sullivan \& Heffernan, 2016). Consequently, this research applies an integrated STEAM with programmed papercutting lamp. The research background is to understand if this paper-cutting project could develop cross-disciplinary skills (consolidating art and technology) and increase students' creativity. 


\section{Research purpose}

Since STEAM education has been constructed mainly with experimental education or maker project-based curriculum, STEAM education brings a positive influence on students in their learning process. This paper centers on the role of ART to implement project-based learning of the STEAM curriculum. We further discuss whether the creativity of primary school students are affected by the STEAM curriculum. By doing so, we integrate both Project Based Learning and creative thinking approaches to develop the STEAM curriculum-The Micro:bit Paper-cutting Lamp. The teaching tools are (1) the program design used in Micro:bit, a microcomputer controller developed by BBC, and (2) paper-cutting, a traditional Art. PBL will be adopted to design the STEAM curriculum so the researcher can understand how the curriculum affects the creativity of senior students in primary school. The outcome could be set as an example of developing a STEAM curriculum in the future. In short, the research purposes in this paper are as follows: (1) how to integrate the program design of Micro: bit with paper-cutting lamp for the project-based STEAM learning. (2) how the creativity of students changes in the STEAM paper-cutting lamp project.

\section{Literature review}

\section{STEM and STEAM education}

STEM education is the foundation for STEAM education. STEM is defined as a model to integrate Science, Technology, Engineering, and Mathematics into a curriculum to prepare students for higher education and for their future to be talents for the knowledge industry. In the STEM education, students are expected to (1) participate in research, (2) equip logical reasoning ability, (3) have a skill of cooperation, and (4) perform an analytical skill (Maryland State Department of Education, 2012). In a word, STEM education not only looks into teaching cross-disciplinary knowledge but pays more attention to the learning process of students with the combination of learning and their daily life. Put another way, STEM education is not just about consolidating different disciplines, but educators should also pay more attention to the interaction between subjects as well as the correlation between subject knowledge and pedagogical content knowledge. (Capraro et al., 2013). STEM is being stressed in science education in America as the educators can incorporate a curriculum with science development at that time so that students could understand the concept and eventually apply in a real situation after the practice, and the discussion (Chang \& Yang, 2013; Salinger \& Zuga, 2009).

Moreover, STEM talents focus on capability development with divergent thinking, whereas art talents value divergent thinking. STEAM education puts together both thinking models so that to cultivate talents with a cross-disciplinary integration skill and creativity. At the same time, STEAM makes up for what is missing. STEAM, therefore, highlights the role of ART based on the STEM (Chien et al., 2017). Land (2013) also pointed out that although STEM fosters students to have strong analyzing skills to design a solution, they still need more creativity to put into practice. A cross-disciplinary approach is used in STEAM education to enable teachers to teach Science, Technique, Engineering, Art, and Mathematics. Also, teachers are able to guide students to absorb constant updated professional knowledge and adapt rapid-changed society. STEAM focuses on analyzing the 
knowledge connection between different subjects, discussing problems, and figuring out how to practice into the real situation. Instead of focusing on one specific subject, STEAM education encourages students to learn by consolidating subjects and proceeding a crossdisciplinary way of thinking to solve problems in the real situation.

However, there are two similarities between STEAM and STEM. As per Brown, Brown, Reardon \& Merrill (2011) stated, STEAM education is a model that applies approaches such as problem-solving and inquiry-based learning to incorporate multiple subjects. STEAM changes from a traditional teacher-centered class, to a new form, which allows students to find the solution actively in real life. Besides, Yakman (2008) reviewed previous studies and established a theory to analyze and structure science, technique, engineering, art, mathematics, and so on. These studies evince the relation between practical content of all subjects and research. Integrating art with STEM could create a brand-new field (Liao, 2016). In short, Banks and Barlex (2014) classified above STEM subjects a coordinated approach; a collaborative approach and an integrative approach. Despite integrating disciplines, this brand-new field exceeds the limitation. Under this circumstance, the development of STEM started to turn toward STEAM, the education with humanity and technology, to build a creative society. In short, art is essential for exploring and practicing cross-discipline.

\section{PBL and STEAM}

The new focus in education reform requires application, creation and ingenuity in terms of creative development. In one of the initiatives to promote creativity among students, STEAM involves the critical process of creativity and innovation. It allows students to connect to the established elements of STEM in art practices, design principles and assessment (James, 2016). These STEAM components include an integrated approach to learning that requires an intentional connection between standards, assessments and lesson design. The core standard of STEAM promotes inquiry, collaboration and emphasizes on project-based learning approach, which assimilates the authenticity of art curriculum (Oner et al., 2016).

Besides, Problem Based Learning (PBL) approach has been stimulated by the STEAM elements, as students participate in designing challenges that incorporate all of these aspects (James, 2016). The synergy of these collaborative subjects are critical skills in the twenty-first century. These skills lead to changes in the implementation of art education pedagogy through a diverse, multicultural authentic learning.

Project Based Learning (PBL) is a teaching method designed for students to practice like working in real life systematically. PBL involves a dynamic classroom approach, which emphasizes long-term learning and interdisciplinary (Hawari et al., 2020). PBL is based on Piaget's and Dewey's theory on constructivism that encourages students to carry out tasks based on 'real-life' experience (Govers et al., 2014). PBL involves a dynamic classroom approach, which emphasizes on long-term learning, interdisciplinary and student-centered art activities (Hawari et al., 2020).

Moreover, the PBL earning model emphasizes contextual learning through complex activities such as giving students freedom to explore and plan learning activities, carry out collaborative projects, and ultimately produce a product (Adriyawati, et al., 2020). Therefore, integration of STEAM- PBL into science learning encouraged students to be able to see the relevance of science knowledge of phenomena in daily life, develop curiosity and problem solving, and increase students' courage to ask questions and explore various sources to find information (Adriyawati et al., 2020). 
As for the project of paper-cutting art in this paper that transformed from paper-cutting decorations, students are required to use the different variety of the sources, such as paper texture, and to apply a new material to design paper-cutting arr. The previous study suggested that the paper cutting has its advantages to preserve the traditional style and add a modern design, or to include interaction beyond plat paper and utilize new techniques to display the sense of tradition $(\mathrm{Ni}, 2012)$. Therefore, the researcher chooses the "Teaching for creative thinking" model to construct this paper-cutting STEAM project, and the "Creative Problem Solving" approach to proceed with teaching-related activity in the class.

The STEAM curriculum of this paper cutting art is designed based on PBL. It integrates modern technology and traditional Chinese paper-cutting, as well as the evaluation board in Micro:bit for interactivity (BBC, 2017; Sentance et al., 2017).

In summary, field experts have realized that students can improve their divergent thinking through art education (Land, 2013). STEAM education, integration of art and STEM, benefits students to learn cross-disciplinary connections from different points of view; enhance the capability to solve problems with knowledge. A, art field of STEAM, stands for social studies, language, physical, musical, fine, performing, and so on. Under such structure, students would be more attached to humanities after logical reasoning training. Compare with current STEM research, Taiwan is lack of STEAM study. Additionally, the art-based curriculum is undeveloped. Therefore, this research will develop a STEAM curriculum with technology and paper-cutting, traditional art, then to discuss the connection between its outcome and creativity.

\section{Integrating creative problem solving into STEAM PBL}

Constructivism is the foundation of project-based learning, which addresses student-centered activities. Teachers are the assistance to guide students to complete projects on their own, find a solution, and verify it. The process helps them to improve their skill of cooperation in a group (Kokotsaki et al., 2016). The PBL process is to set up the goal, lay out the plan, design "leading question", assess the initial plan and draft processional plan and process management (Ravitz, 2008). PBL provides a learning environment for students to participate actively in a project and solve problems in real life. Students could reach their achievement, communicate with fellows, and improve their creativity to solve problems in learning autonomy (Cheng et al., 2007).

Project-based learning could stimulate the interest of students towards learning (Chang $\&$ Chen, 2018). In STAEM education, students would be equipped with rigorous logical reasoning but not with the emotional facet of culture. Art is the key to successful innovation (Brady, 2014; Ejiwale, 2013).The integration of art and technology leads to a special skill, by which students could analyze the complex problem with convergent thinking and practice the solution in the real situation with divergent thinking. For instance, Hentiksen (2017) discussed integrating the curriculum with Spanish, the language, and the water cycle. Above project-based learning found out that design thinking helps teachers to organize the STEAM curriculum.

STEAM is a way to improve creativity. STEAM in art education not only teaches students art but also educates them to use it in real life and always to think about how to improve the way of living and society. The STEAM curriculum should connect with modern technology development (Chang \& Yang, 2013) and include humanity so that students can apply learning strategies such as problem-solving and inquiry-based learning to incorporate multiple subjects. As for PBL, it is a model for implementing a curriculum, which 
leads to the completion of an artwork. This research integrates the art of paper-cutting and technology to improve the creativity of students. The following chapters will discuss traditional Chinese paper-cutting and the art of paper-cutting separately.

The PBL of paper-cutting in this paper may help students in primary school to development the creativity. Yang (2015) studies the second-year students in primary school and their paper-cutting activity. The research pointed out that students understood better regarding the art of paper-cutting and tradition. Also, the result of TTCT (Torrance Tests of Creative Thinking) shows their creativity was improved after paper-cutting activity. The most important is that students are able to come up with creative ideas as they needed to design the style. Wang (2014) explained that the brainstorming approach of creative thinking allows students to come up with a paper-cutting design, arrange compositions, apply color personality and think creatively. Similarly, Song (2020) showed that digital fabrication technologies had positive overall effects on preservice teachers' learning in the following areas: problem-solving skills et al.

The core of creativity includes innovation, personality, and a supportive environment. After the creative thinking process, people can solve problems or create products. The core of creativity and the demand of products come from real life (Amabile, 1983; Mao et al., 2000). Creativity is the capability to create an innovative idea, invention, or artwork. They have to be identified by experts as products containing technology, aesthetic, or social value (Vernon, 1989). The foundation of "teaching for creative thinking" is creativity theory. "Teaching for creative thinking" is to motivate students, encourage them to create, and to cultivate their creativity. "Teaching for creative thinking" aims to enhance the cognitive ability of divergent thinking and creative personality. The cognitive ability of divergent thinking refers to fluency, flexibility, originality, and elaboration (Chou, 2013; Mao et al., 2000; Williams, 1972). Originality is a novel and unique thinking ability, which an individual is able to respond differently than others and produce a distinctive outcome. The low the similarity, the higher the originality (Mao et al., 2000; Williams, 1972; Williams, 1972). In this regard, Isaksen, Dorval and Treffinger address the "Creative Problem Solving" with three dimensions and six steps (Chang, 2013). The existing approach provides a comprehensive view for educators to imagine and plan theirs course. This research adopts the revised version of Creativity Assessment Packet (CAP) (William, 1972; Lin \& Wang, 1994; Mao et al., 2000). CAP is to review the outcome of practicing the "teaching for creative thinking" model. It can evaluate six teaching goals (fluency, openness, flexibility, originality, elaboration, and title) and four creative personalities (adventurous, curious, imaginative, and challenging).

In conclusion, STEAM PBL encourages students to see the world through a science perspective. Art allows people to enrich the world beautifully; engineering and technology enable people to change the world for the demand of society; mathematics offers as a thinking method and analysis tool, which people use to develop science, engineering, art, and technology. In STEAM PBL, the curriculum helps students to understand science and technique, then explore technology and art while building their artwork.

\section{Research method}

The researcher follows the instruction in PBL and designs the STEAM curriculum of this research. Considering the content of the STEAM curriculum and the fact that Taiwan is lack of an art-oriented STEAM curriculum, the researcher builds the curriculum 
based on BBC micro:bit, microcomputer controller, and traditional Chinese paper-cutting. All areas of STEAM are covered in the curriculum of this research.

\section{Research design}

The research design incorporated the method of one-group pretest-posttest design. The teacher who delivered the curriculum is from the research team. There was a total of two weeks teaching, $240 \mathrm{~min}$ per week (total $420 \mathrm{~min}$ ). Two tests, CAP pretest and CAP posttest, were carried out before and after teaching for quantitative analysis. The researcher organized and analyzed the collected information in order to understand the effect of experimental teaching on creativity. Apart from that, curriculum worksheets and artworks were collected after teaching for qualitative study along with observation records taken during the class. It allowed the researcher to analyze the effect of implementing the "teaching for creative thinking" model in the STEAM curriculum towards the creativity of senior students in primary school.

The revised version of Creativity Assessment Packet done by Lin and Wang (1994) were applied in this research. The assessment includes the Test of Creative Thinking and Creative Tendency Scale. The reason to consider Williams Scale was that the researcher believed that both cognitive and emotional behavior are strongly related to creativity in project-based STEAM. In this case, the scale could help study the change of creativity among students (Williams, 1972). The internal consistency reliability of this scale is between $0.401 \sim 0.877$; retest reliability is between $0.438 \sim 0.810$; inter-rater reliability is between $0.878 \sim 0.992$. Their correlation coefficients are all above 0.05 , which is a significant performance. As for validity, TTCT is a criterion and the performance is between $0.261 \sim 0.545$. The cronbach alpha reaches over 0.5 , which is beyond the standard (Lin \& Wang, 1994).

\section{Participants}

The research subject was a class of senior students from a primary school in Taichung City in Taiwan. Total of 21 students with 9 males and 12 females involving in this research. The participated primary school adopts heterogeneous grouping every year. Students were asked to sign an agreement. Besides, the participated primary school signed a corporative agreement with the National Taichung University of Education, which stated the teaching is conducted after class only when the class teacher agreed to assist this research.

\section{Project-based STEAM curriculum design}

The researcher followed the instruction in PBL to designs the STEAM curriculum of this research. That was to: (1) set up a goal and draft a plan, (2) design "leading question" (3) assess the initial plan (4) draft a professional plan and management process. Finally, three university professors and one specialist teacher evaluated and discussed the PBL of the curriculum. Expert validity was used to review the correlation and clarity. 


\section{Content analysis of STEAM curriculum}

The curriculum focused on the combination of art and technology and together with the application of mathematics, engineering, and science to complete activities and produce artworks. To begin with, goal setting is the first step towards planning The content analysis of the curriculum and teaching goal is shown in Table 1. It is the content analysis based on Micro:bit paper-cutting lamp, project-based curriculum, with other elements of STEAM.

\section{STEAM teaching object for art light}

STEAM teaching objective was to: (1) learn circuit connection, (2) learn to apply circuit to the daily life, (3) understand the combination of color and light in optics, (4) understand the technology of interactive paper-cutting lamp, (5) understand Blocky, (6) learn the art papercutting, (7) integrate paper-cutting and modern technology, (8) improve the creativity of students, (9) enhance the problem-solving ability(10) build cooperative learning attitude.

\section{Design “Leading Question"}

There were several leading questions prepared for this project-based activity: (1) how to consolidate paper-cutting with modern technology? (2) how to use sound and movement to control light? (3) how many ways you can come up with to control paper-cutting lamp? The students will understand the mathematical concept in program design while using Blocky.

\section{Curriculum assessment}

The assessment was for the teacher to understand the learning progress of students, and adjust the teaching if needed. The curriculum assessment includes curriculum worksheets and CAP.

\section{Design PBL plan}

The assessment was for the teacher to understand the learning progress of students, and adjusted the teaching if needed. The curriculum assessment included curriculum worksheets and CAP.

\section{Design PBL plan}

There were four main activities. The content of teaching was the integration of science, technique, engineer, and art. Picture 1 shows the content of each activity and related STEAM curriculum (Table 1). The teaching began with CAP pretest for $30 \mathrm{~min}$, followed by 360 projectoriented learning (Fig. 1). The teaching was completed by a 30 min of CAP posttest.

\section{STEAM curriculum material}

STEAM curriculum material consisted of teaching for program design teaching and papercutting. Curriculum Material were discussed in this chapter. 


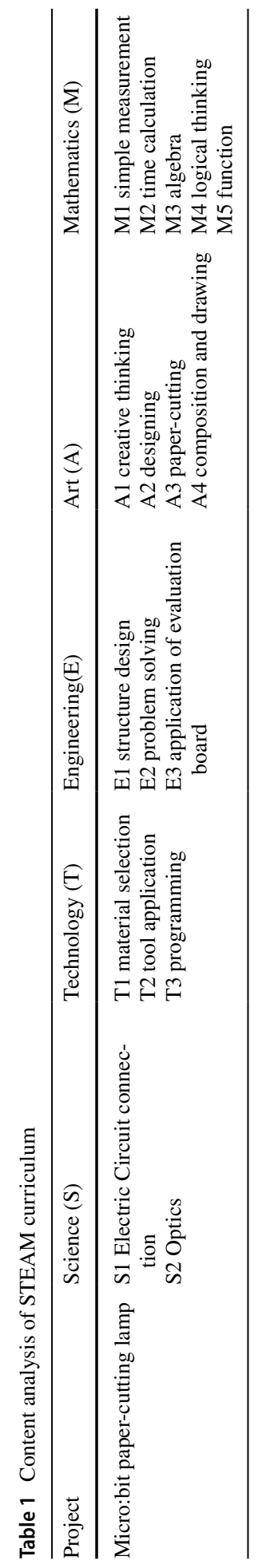




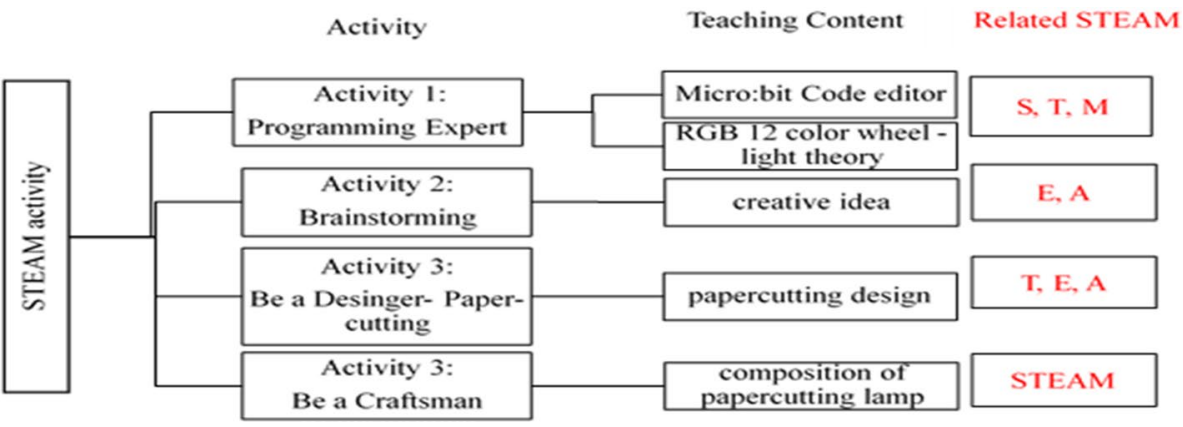

Fig. 1 PBL of the curriculum and activity plan

\section{$\mathrm{BBC}$ micro:bit program design}

Teaching for program design and paper-cutting were two materials in this STEAM curriculum. The program design taught students with program logic (Table 2). Once the students learn how to apply program logic to connect the sensor, bull, and loudspeaker, they started to combine and design light art functions and created their program design for Micro:bit paper-cutting light lamp. Through this, they could learn about mathematics, algebra and function.

\section{Material for paper-cutting lamp}

The teaching material for the paper-cutting lamp was designed by the researcher (Fig. 2). Paper-cutting technique was required to consider three layers, the foreground, the middle ground and the background. This design allowed students to learn Thirds and a space concept. The researcher prepared three layers of paper for students to design their patterns with the worksheet. Table 3 shows all required materials and resources prepared by the teacher: BBC Micro:bit microcomputer controller, Grove gesture recognition sensor, ws $2812 \mathrm{~b} 5 \mathrm{v}$ LED light strip, boxes for the light, paper cut sculpture designed by students and box for lights and electric component.

\section{Structure of curriculum}

The structure of this curriculum was based on the five sectors of STEAM. The researcher applied PBL for designing curriculum content and the "teaching for creative thinking" model for organizing material. It was designed to highlight cross-disciplinary integration and the application of "teaching for creative thinking" for creativity improvement. Figure 3 shows the structure of the curriculum. 
Table 2 Teaching content for program design

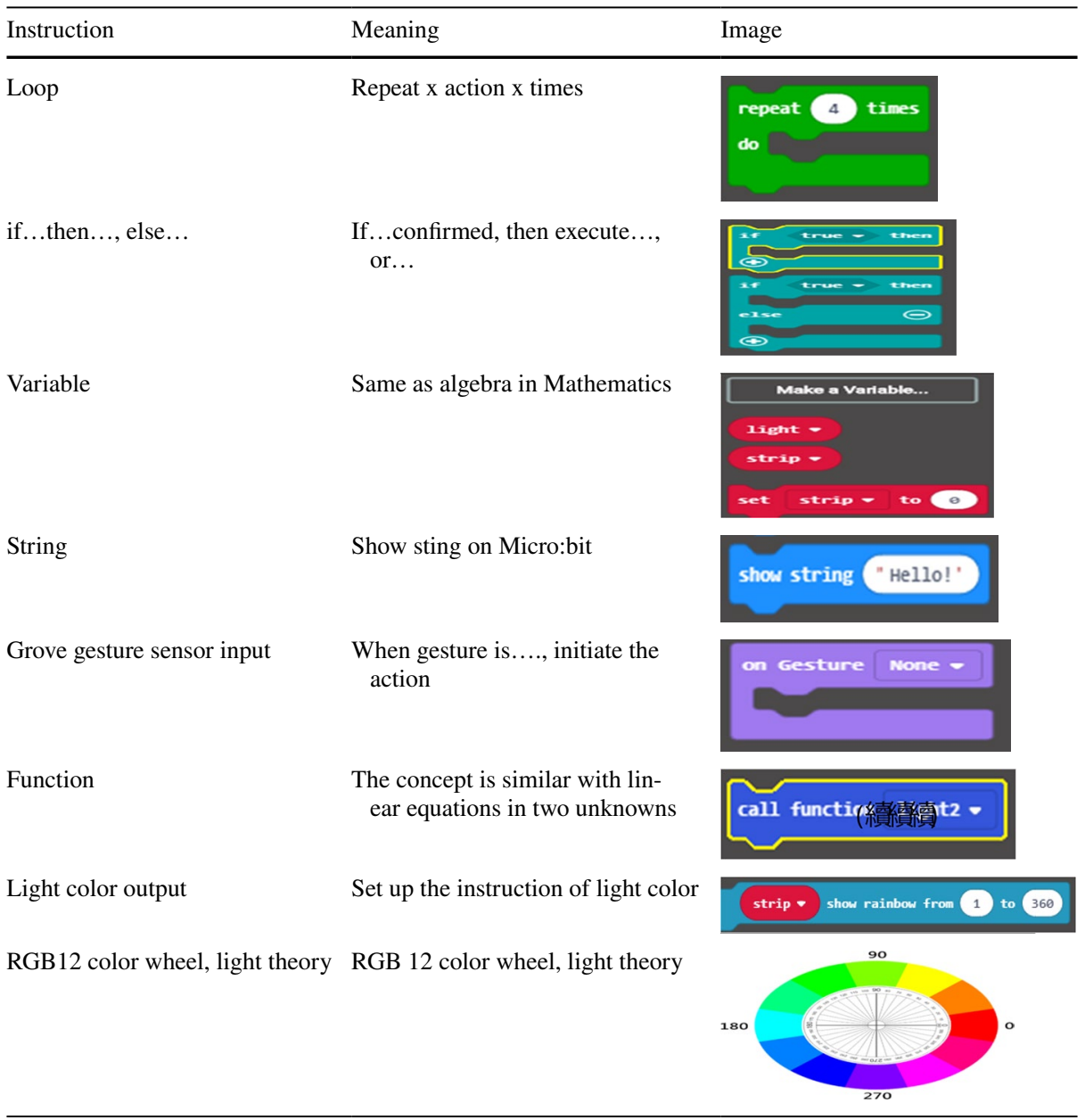

Fig. 2 Paper-cutting framework

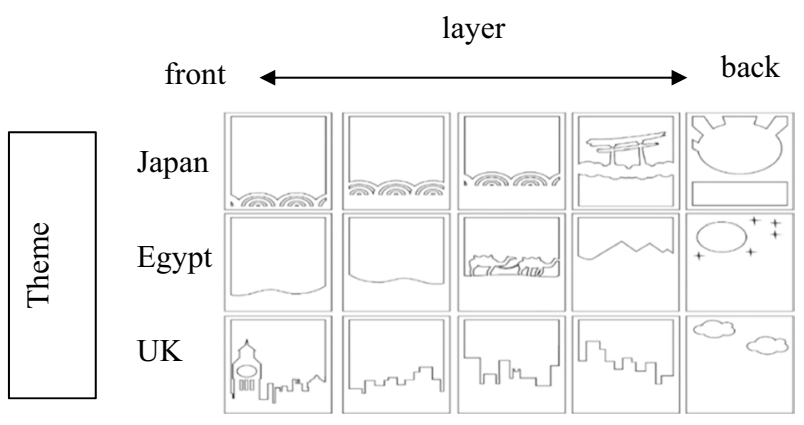


Table 3 Material for Papercutting lamp

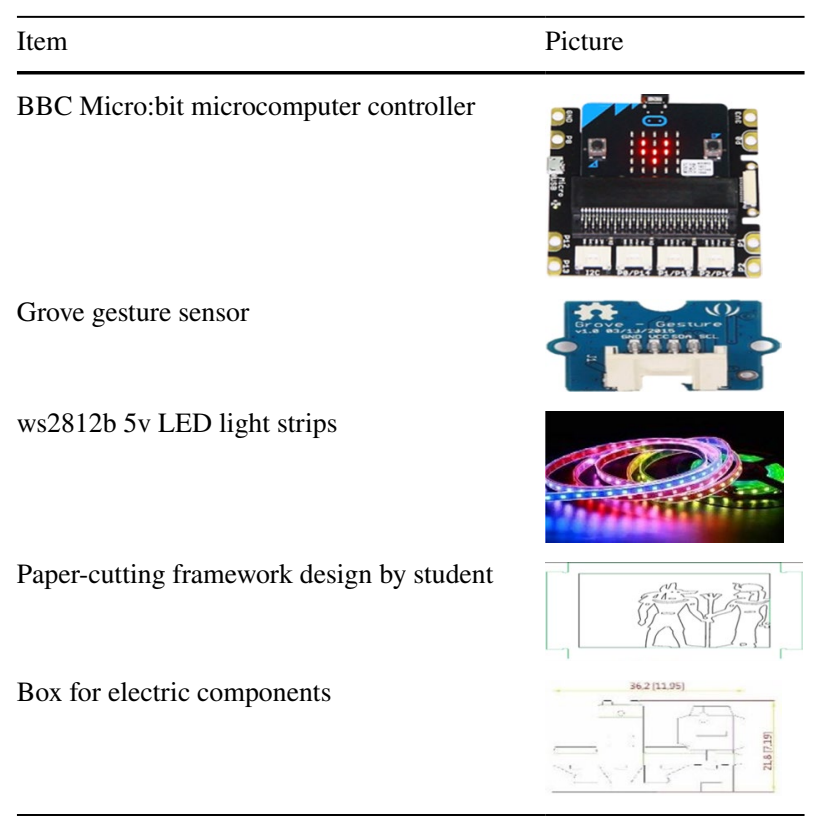

\section{Result and discussion}

This section will first discuss the effect of the application of the PBL oriented STEAM curriculum toward creativity, then analyze and explain the process of implementation.

\section{PBL oriented STEAM curriculum toward creativity}

The research first looks into the PBL oriented STEAM curriculum, and use t, the dependent sample, to verify the effect after students participating in the curriculum.

\section{Cognitive facet}

The evaluation is in line with the Test of Creative Thinking Activity to study the creativity of students in the cognitive facet. It includes fluency, originality, flexibility, elaboration, openness and title. Among these different aspects, fluency has a maximum of 12 points, originality is 24 points and flexibility is 12 points and openness is 36 points. The total is 156 points.

\section{The change in cognitive facet of creativity}

As Table 4 shows, it is the result of each aspect in the cognition level of creativity after students receiving the STEAM curriculum. Fluency is $t=1.14, p>0.05$; openness is $\mathrm{t}=8.0, p<0.05$; flexibility is $t=2.27, p<0.05$; originality is $t=6.86, p<0.05$; elaboration 


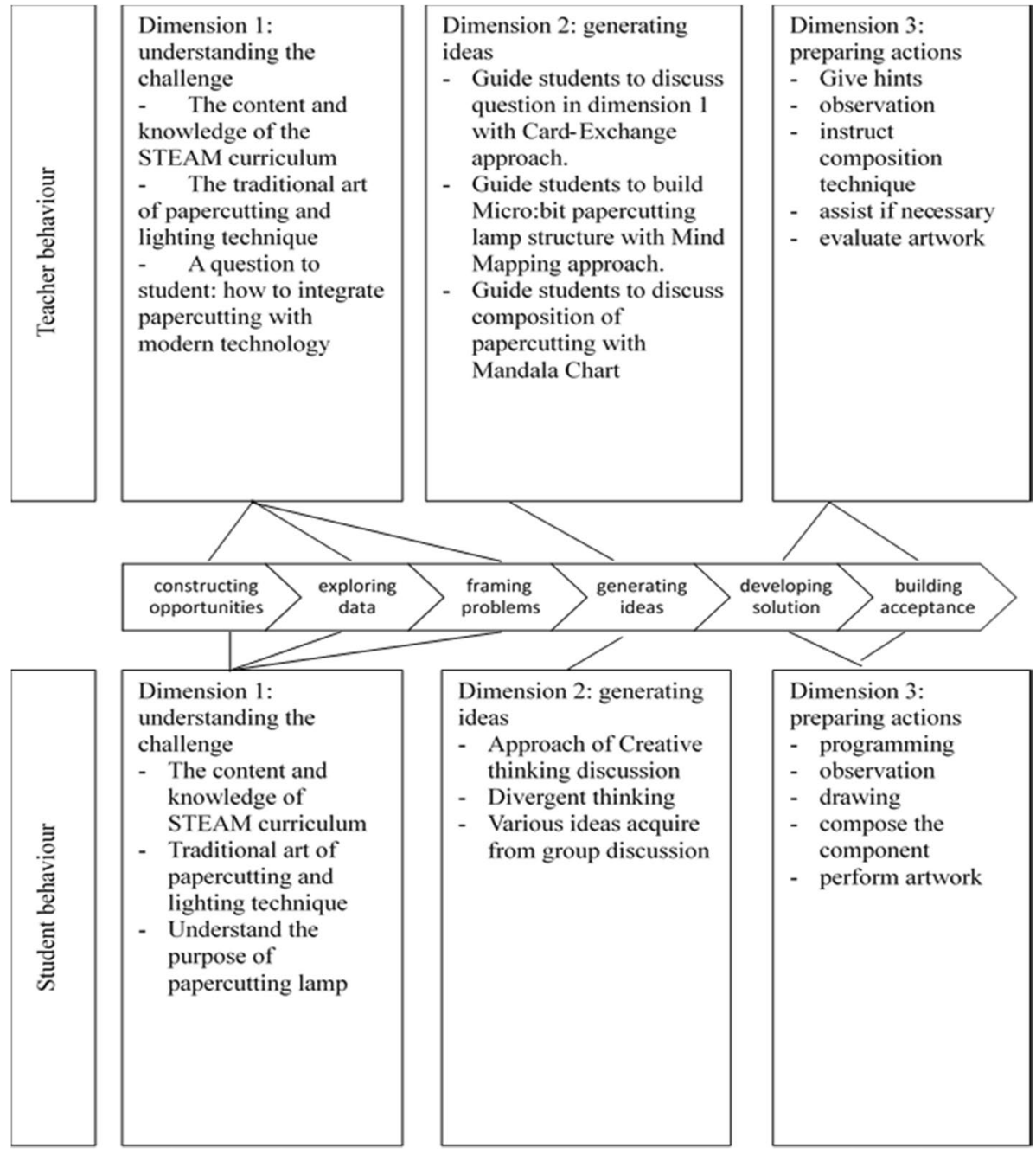

Fig. 3 STEAM curriculum structure and process for practice

Table 4 The result of CAP Pretest and Posttest

\begin{tabular}{|c|c|c|c|c|c|c|}
\hline \multirow[t]{2}{*}{ Creativity } & \multicolumn{2}{|l|}{ Pretest } & \multicolumn{2}{|l|}{ Posttest } & \multirow[t]{2}{*}{$t$} & \multirow[t]{2}{*}{ Significant } \\
\hline & $M$ & $S D$ & $M$ & $S D$ & & \\
\hline Fluency & 11.40 & 2.35 & 11.96 & .21 & 1.14 & .265 \\
\hline Openness & 15.57 & 3.50 & 27.91 & 6.50 & 8.05 & .000 \\
\hline Flexibility & 6.48 & 1.68 & 7.30 & 1.22 & 2.27 & .034 \\
\hline Originality & 16.74 & 3.18 & 25.52 & 6.35 & 6.86 & .000 \\
\hline Elaboration & 10.57 & 2.78 & 20.26 & 6.90 & 7.33 & .000 \\
\hline Title & 11.87 & .97 & 15.52 & 4.30 & 3.75 & .001 \\
\hline Total & 72.60 & 7.52 & 108.48 & 19.40 & 8.59 & .000 \\
\hline
\end{tabular}


is $t=7.33, p<0.05$; theme is $t=3.75, p<0.05$. The total of all is $t=8.59, p<0.05$. While comparing the result of the pretest and posttest, openness, flexibility, originality, elaboration, title and total has improved significantly.

\section{Emotional facet}

The evaluation is under the revised version of the CAP. It is to study the creativity of students in emotion facet, which includes adventurous, curious, imaginative, and challenging. Among the four aspects, ambitious has a maximum of 33 points, curiosity is 42 points, imagination is 42 points and challenge is 36 points. The total is 150 points.

Table 5 shows that there no significant improvement among curious, imaginative and challenging, though the average increased. The result reflects that the creativity of emotional facet would not be affected after students receiving the STEAM curriculum.

\section{Practice of PBL oriented STEAM curriculum}

\section{Activity 1: program expert}

The program design taught student program logic step by step together with tasks. The detail is shown in Table 6, which was suitable for a senior student in primary school. The student followed the instruction to apply program logic to connect the sensor, bull and loudspeaker. Then, they were asked to design light art functions and create their program design for Micro:bit paper-cutting light lamp. There were two processes.

Initially, students completed the task at each step. After teaching them the blocks, the teacher gave students the tasks (Table 6) to students to complete on their own. Tasks were done orderly. Second, the student finished the program design. Once they connected BBC Micro:bit with gesture recognition sensor, the light and Micro:bit display-panel were changed as the gesture changes. Student can press a bottom to turn of the light and Micro:bit display panel.

There were two individual tasks and one group task. All students completed the simple individual task on time. As for the percentage of completing the advanced individual task is $72.54 \%$. However, the rate goes up to $78.57 \%$ from the advanced individual task to the group task. Table 6 presents all of the success rates. The result implies that group corporation could increase the succession.

Lastly, once they connect BBC Micro:bit with gesture recognition sensor, the light and Micro:bit display panel were changed as the gesture changes. Students pressed a bottom

Table 5 Result of test of creative thinking

\begin{tabular}{|c|c|c|c|c|c|c|}
\hline \multirow[t]{2}{*}{ Creativity } & \multicolumn{2}{|l|}{ Pretest } & \multicolumn{2}{|l|}{ Posttest } & \multirow[t]{2}{*}{$t$} & \multirow[t]{2}{*}{ Significant } \\
\hline & $M$ & $S D$ & $M$ & $S D$ & & \\
\hline Adventurous & 24.08 & 2.13 & 23.91 & 2.29 & -.339 & 738 \\
\hline Curious & 28.47 & 3.11 & 29.00 & 3.26 & .959 & .348 \\
\hline Imaginative & 27.34 & 2.08 & 27.82 & 3.63 & .807 & .428 \\
\hline Challenging & 25.04 & 2.14 & 25.82 & 2.74 & 1.258 & .222 \\
\hline Title & 107.60 & 6.22 & 109.34 & 8.88 & 1.183 & .250 \\
\hline
\end{tabular}




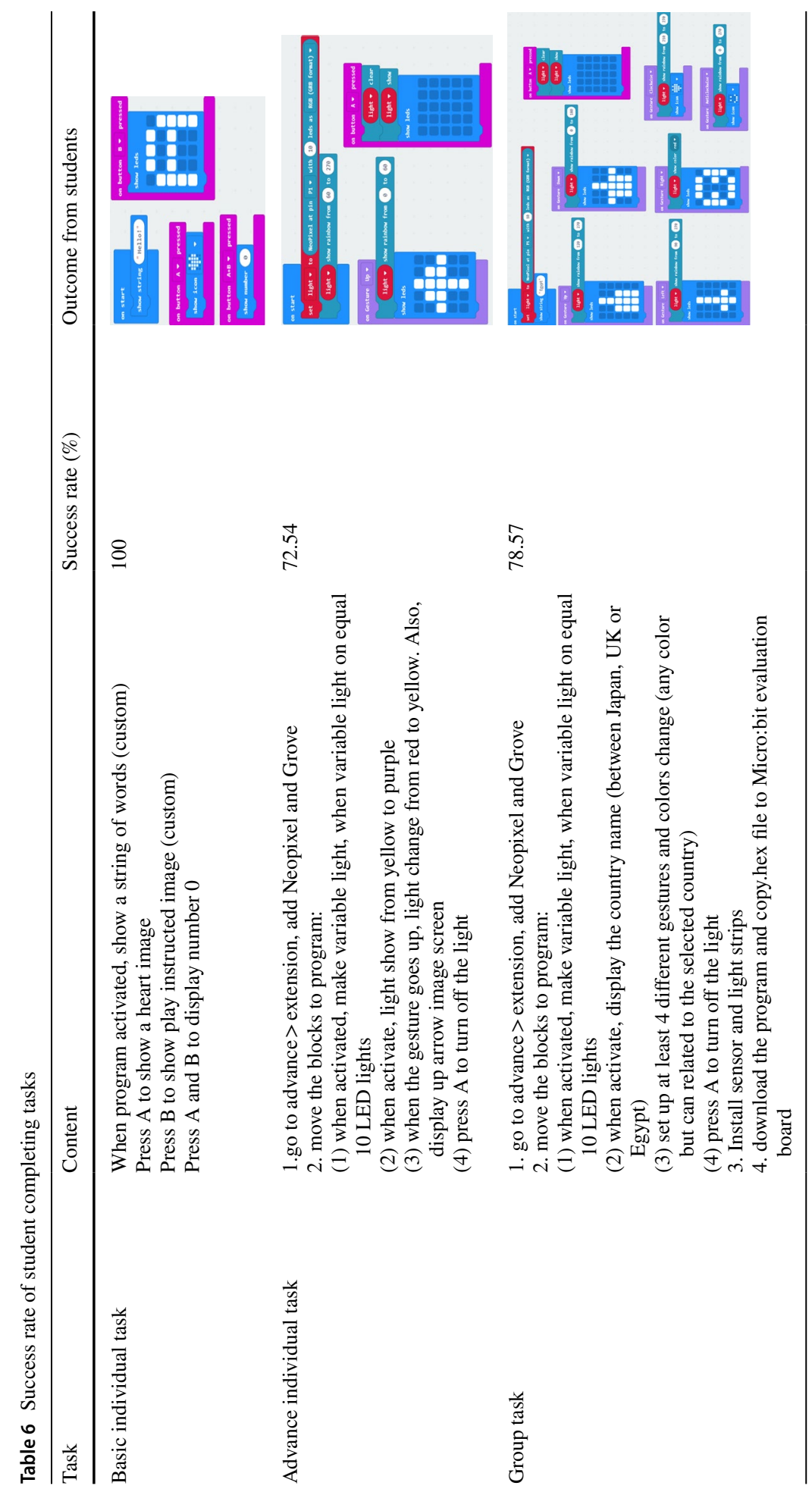



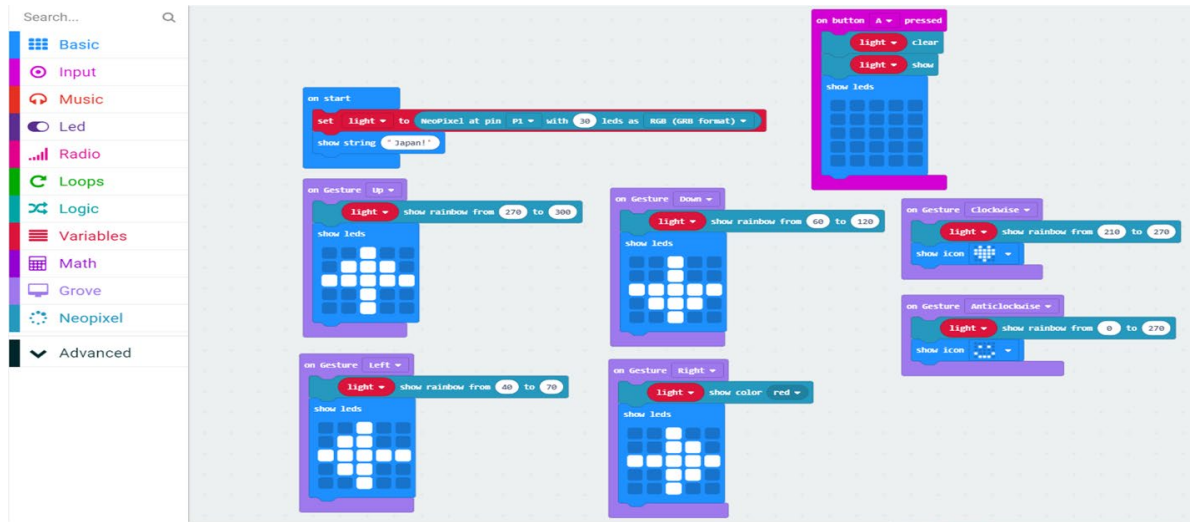

Fig. 4 Sample of program design

to turn of the light and Micro:bit display panel. Figure 4 shows the completed program design.

\section{Activity 2: brainstorming}

Students were divided into groups to brainstorm a theme based on a country. It could be an animal, an item, a toy, a building, a legend, a plant, a costume, a food and a view of that country. Table 6 shows the theme that students came up with within a given time. In short, brainstorming helped students to develop divergent thinking skills, as well as to enhance the fluency and openness in cognitive facet of creativity. Fluent thinking refers to how eloquent is the thinking process, how broad thinking can be extended and how many an individual can produce (Chou, 2013; Mao et al., 2000; Williams, 1972). Students were encouraged to do research and discuss with fellows. Those attempts could affect fluency. As for openness, it is the ability to accept different opinions. In this research, students could communicate with the teacher and fellows and accepted different opinions. Therefore, openness increased undoubtedly. The above finding also echoes the result in Table 4.

As per Table 7 listed, students were able to give at least 10 or more than 30 related things through brainstorming in a short period. Brainstorming enabled students to put forward different opinions for one topic, by which their flexibility was stimulated. Students were brainstorming in the group discussion in Fig. 5.

Table 7 list of brainstorming

\begin{tabular}{lllllllllll}
\hline Group & Theme & \multicolumn{7}{l}{ Numbers of related things } \\
\cline { 3 - 10 } & & Animal & Food & Plant & Toy & Building & Legend & Costume & View & Total \\
\hline 1 & Egypt & 4 & 3 & 4 & 4 & 5 & 4 & 4 & 3 & 31 \\
2 & Egypt & 1 & 1 & 2 & 1 & 2 & 1 & 1 & 3 & 12 \\
3 & UK & 4 & 3 & 3 & 3 & 4 & 3 & 1 & 3 & 24 \\
4 & UK & 1 & 3 & 2 & 2 & 2 & 3 & 1 & 3 & 17 \\
5 & Japan & 3 & 3 & 4 & 2 & 3 & 3 & 1 & 3 & 22 \\
\hline
\end{tabular}




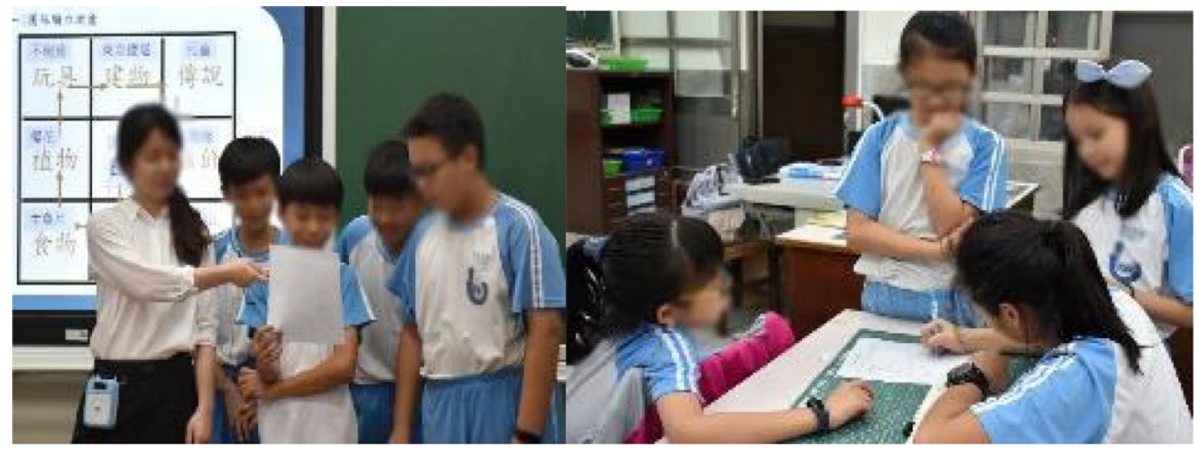

Fig. 5 Activity 2-Brainstoming

\section{Activity 3: be a designer-paper-cutting lamp}

The "Teaching for creative thinking" model gave students a chance to think of different form of a pattern related to the theme. It could be an animal, a building, a legend, a view, a plant, a costume, a food and a toy. Figure 6 is an example of a draft design by students. Through the brainstorming process, students could think from a different angle to present with the ability of openness. Figure 7 is how students were practicing. Looking into the technique of paper-cutting, the paper patterns done by students were inconsistent or even broken because they were unable to identify Yin and Yang carving in the beginning. Yin carving means to cut the shape out and remove it, keep what is left outside of the pattern. Yang carving means to cut the shape out and keep it, remove the piece outside of the pattern. However, the curriculum indeed develops the elaboration of cognitive facet of creativity. In the end, students could submit a suitable paper-cutting pattern (Fig. 8).

Elaboration refers to the ability to turn a simple creation into a fine product, to revise an idea and extend the thought (Chou \& Yung-Chieh, 2013). Students encountered several problems, for instance, there were inconsistent patterns or cracks during the design. Students kept trying to revise their previous idea and then were able to complete the artwork and complete the task given by the teacher. The example shows that the elaboration was improved. The outcome also supports the result of Table 4, which shows the STEAM project could benefit the elaboration.

Fig. 6 Draft for Paper-cutting frame done by students

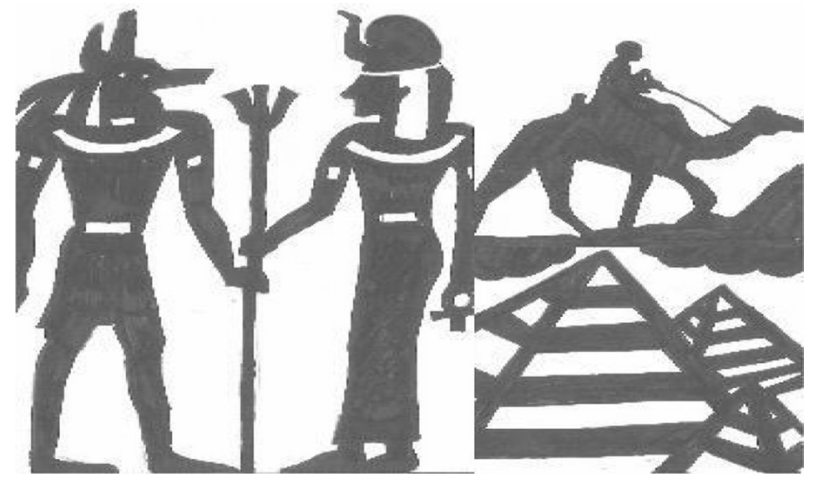




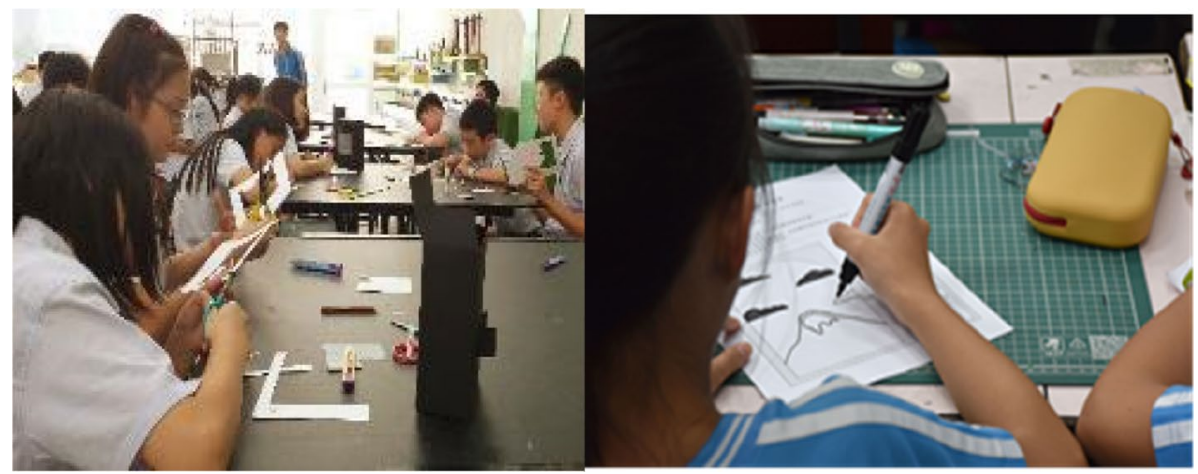

Fig. 7 Process of proacting

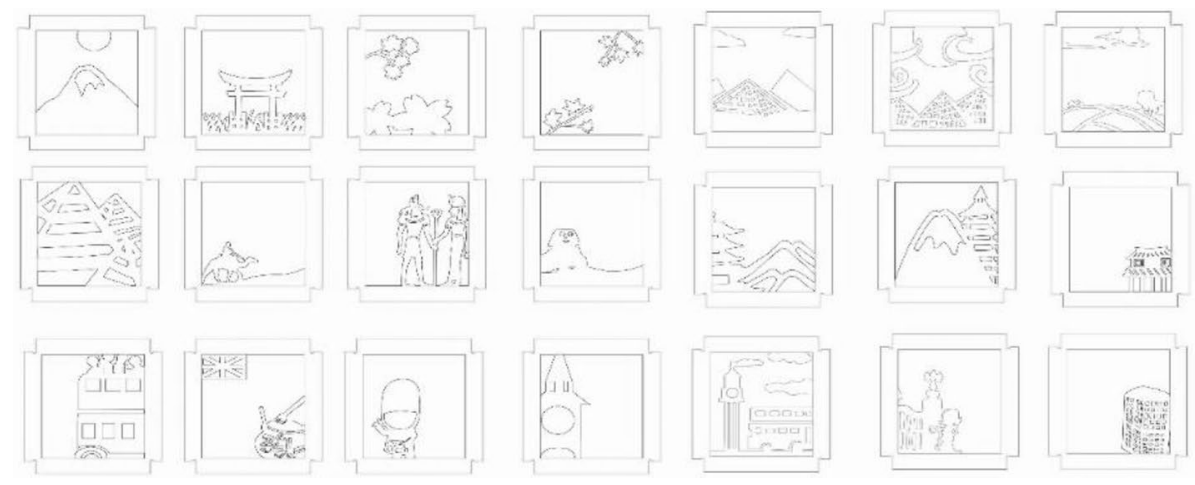

Fig. 8 Paper-cutting pattern designed by students

\section{Activity 4: be a craftsman}

In this activity, students integrated the Micro:bit evaluation board they had done previously with paper-cutting, then connected with the electric circuit to make an interactive papercutting lamp. Through the hand-on activity, they actively participated in the class and tasks as well as cooperated in the group.

Students discussed in the group to figure out how to place shapes into a presentable pattern with foreground, midground and background layer and stereoscopic image (Fig. 9). Figure 10 is the final artwork after integrating light control. The teacher observed in the class and found out that students were communicating and discussing with each other while composing patterns to ensure the aesthetic of the artwork. They were open to different opinions. The layer of foreground, midground and background combine with various colors of light can enrich the artwork.

In short, flexibility is required to be performed comprehensively in activity 4. Flexibility is the ability that a person could express different opinions and think in various ways. The result shows that brainstorming in the "teaching for creative thinking" model allows students to exchange their opinions and discussed in the group, then to think in various ways. Students, under this circumstance, enhanced their flexibility, which were eventually 


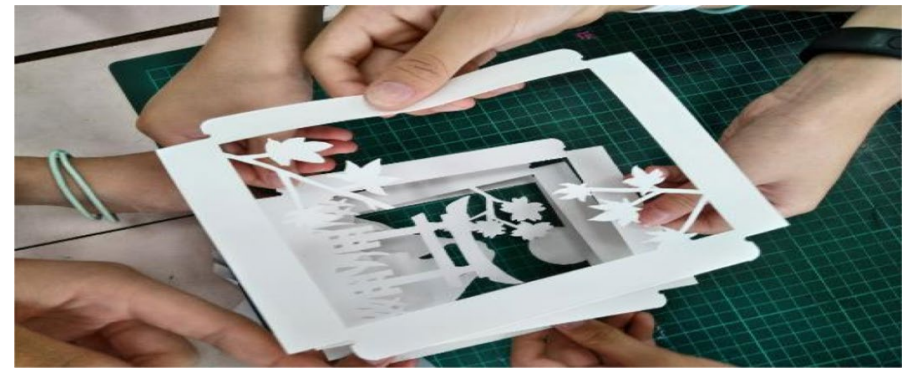

Fig. 9 Practicing activity 4- Be a Craftsman

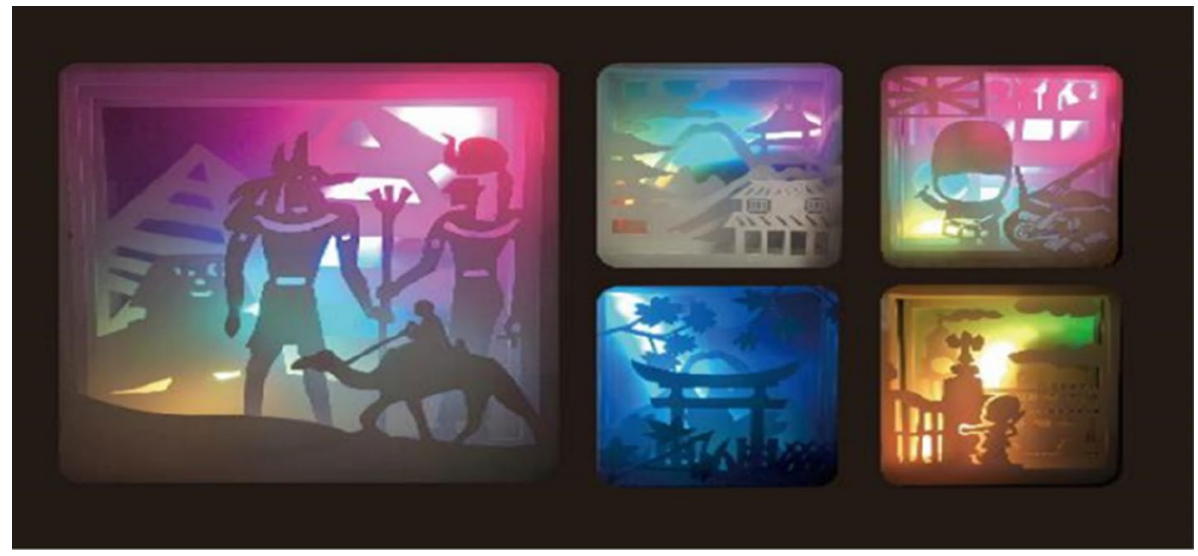

Fig. 10 The completed artwork

be presented in their artwork. As described title, students were able to integrate each skill and art learned previously and then finalized it.

\section{Conclusion and suggestion}

This research aims to integrate Micro:bit program design and paper-cutting lamp to design program-based STEAM exploration and practice curriculum. Besides, the research applies the "teaching for creative thinking" model to build up activities. Teaching objects are presented in first-level activity, which is to understand algebra and function. In the secondlevel activity, brainstorming and paper-cutting worksheet allows students to cooperate in the group. The entire process helps to increase openness. Moving into the third-level activity, students learn to design paper-cutting patters, adopt depth of field the space concept and integrate electric circuits with light composition to adjust light and shadow. It is essential to have elaboration to cope with the difficulties while designing the paper cutting. Lastly, the activity "Be a Craftsman", students produced their artwork by combining the paper-cutting and Micro:bit the light control program. 
This study has shown that STEAM PBL enables primary school students to improve deduction and induction and such logical reasoning ability in the software programing. Besides, it helps them strengthen their flexibility and adaptability needed in problem-solving so they could have a skill of cross-cultural communication in terms of paper-cutting. Different from regular course, which is to instruct knowledge, STEAM PBL is to educate students to connect knowledge from different subjects, solve problems and innovate. Under this circumstance, students continuously improve their problem-solving capability, innovation ability, the skill of cooperation, and creativity. We echoed previous study of Chen $\&$ Chang (2018) that compared the integrated robotic curriculum and the regular robotic curriculum and found out that students 'knowledge is improved and interest is stimulated when students learn through an integrated curriculum.

In addition, this paper demonstrated that art could be the foundation of STEAM education, in which students interpret science and technology with the support of engineering and artwork. Besides, STEAM teaches students to know the world through a cross-disciplinary point of view, to change the world with innovation, and to develop their innovative ability. During the teaching, students will be guided to cooperate and practice in order to complete the project and figure out the difficulties encountered in real life. Finally, students also are expected to demonstrated color personality in optics and explore creativity when consolidating industrial technology and paper-cutting.

Overall, students are interested in learning during the practical activity in the projectbased STEAM curriculum. The outcome proves that there is an outstanding improvement in the cognitive level of creativity, which reflects on flexibility, originality, elaboration, title and total. In order words, the project-based STEAM curriculum could increase part of the cognitive level of creativity. However, the curriculum of this research is designed for a total of $420 \mathrm{~min}$, equals to 2 weeks intensive STEAM curriculum. The limitation of this research is that it could benefit more on cognitive level of creativity but less on an emotional level. The researcher suggests that future studies could include different angles of technology concept (such as light material) into the STEAM curriculum of Micro:bit paper-cutting lamp. In this case, they could create more mixed media when integrating paper-cutting with BBC Micro:bit evaluation board.

There are some suggestions for teaching and practice based on the observation and the result of this research. (1) From the point of programming language, the program design of this research utilize the gesture sensor and light strips to design a program that could adjust different lights with the change of gesture. Most of the students understand the program logic and can apply it appropriately. Therefore, the researcher suggests more interactive functions can be included in this program design in the future. (2) Given paper-cutting design, the majority of students find it complicated to understand the composition of Yin and Yang carving when learning the technique. Therefore, it is suggested by the researcher that the teacher could spend more time explaining and also presenting an physical object, so that the students could understand easily. (3) The structure design of paper-cutting in this research focuses on layering a flat surface with foreground, midground and background to build the stereoscopic space. The researcher suggests that in the future, it could help to level up the sense of spaces for students when using stereoscopic paper-cutting in STEAM teaching material.

The curriculum of this research only benefits the cognitive facet of creativity. The researcher believes that the reason could be the length of the teaching period. Since the curriculum is only last for two weeks, it is too short to affect the emotional facet of creativity. Future researchers are suggested to extend the teaching period and evaluate whether the time is the cause of this effect. 
Authors' contribution Conceptualization, Professor L and Miss S methodology, Professor L: formal analysis, Professor L and Miss S: data curation, Professor H: writing-original draft preparation, Professor L and Miss S: writing—review and editing, Professor L, Professor L and Professor H: supervision, Professor L.

Funding Not applicable.

Data availability The teaching material and data used and analyzed during the current study are available from the corresponding author on reasonable request. Please contact the author for your requests.

\section{Declarations}

Conflict of interest The authors declare no conflict of interest.

Open Access This article is licensed under a Creative Commons Attribution 4.0 International License, which permits use, sharing, adaptation, distribution and reproduction in any medium or format, as long as you give appropriate credit to the original author(s) and the source, provide a link to the Creative Commons licence, and indicate if changes were made. The images or other third party material in this article are included in the article's Creative Commons licence, unless indicated otherwise in a credit line to the material. If material is not included in the article's Creative Commons licence and your intended use is not permitted by statutory regulation or exceeds the permitted use, you will need to obtain permission directly from the copyright holder. To view a copy of this licence, visit http://creativecommons.org/licenses/by/4.0/.

\section{References}

Adriyawati, A., Utomo, E., Rahmawati, Y., \& Mardiah, A. (2020). STEAM-project-based learning integration to improve elementary school students' scientific literacy on alternative energy learning. Universal Journal of Educational Research, 8(5), 1863-1873.

Amabile, T. M. (1983). The meaning and measurement of creativity. Springer. 1007/978-1-4612-5533-8_5

Banks, F., \& Barlex, D. (2014). Teaching STEM in the secondary school: Helping teachers meet the challenge. Routledge.

Benton, L., Varotsis, G., \& Vasalou, A. (2019). Leading by example: Exploring the influence of design examples on children's creative ideation. International Journal of Human-Computer Interaction, 122, 174-183. https://doi.org/10.1016/j.ijhcs.2018.09.007

Burke, B. N. (2014). 6E learning by DeSIGNTM model. Technology and engineering teacher, March, pages 14-19. Retrieved September 29, 2019, from https://www.oneida-boces.org/site/handlers/filedownload. ashx moduleinstanceid $=1290 \&$ dataid $=2862 \&$ FileName $=6$ E $\% 20$ Learning $\% 20$ by $\% 20$ Design $\% 20 \mathrm{Mod}$ el.pdf. https://doi.org/10.1002/9781119302735

BBC (2017). BBC micro:bit celebrates huge impact in first year, with $90 \%$ of students saying it helped show that anyone can code. Retrieved September 07, 2019, from https://www.bbc.co.uk/mediacentre/lates tnews/2017/micro:bit-first-year

Brady, J. (2014). STEM is incredibly valuable, but if we want the best innovators we must teach the arts. The Washington Post, Innovation, 5, 1-5. September 5.

Brown, R., Brown, J., Reardon, K., \& Merrill, C. (2011). Understanding STEM: Current perceptions. Technology and Engineering Teacher, 70(6), 5. https://doi.org/10.1080/15391523.2016.1146563

Campbell, C., Speldewinde, C., Howitt, C., \& MacDonald, A. (2018). STEM practice in the early years. Creative Education, 9(1), 11-25. https://doi.org/10.4236/ce.2018.91002

Capraro, R. M., Capraro, M. M., Morgan, J. R. (Eds.). (2013).STEM project-based learning: An integrated science, technology, engineering, and mathematics (STEM) approach. Sense Publishers. https://doi. org/10.1007/978-94-6209-143-6.

Chang S. H. (2013). Creativity: theory, technique and teaching. Wunan.

Chang, Y. S., \& Yang, Y. J. (2013). An exemplar of STEM teaching design - hydraulic arm. Science, Technology and Human Education Quarterly, 1(1), 2-17. https://doi.org/10.6587/JTHRE.2014.1(1)

Chang, C. C., \& Chen, Y. C. (2018). Evaluation and design of cross-disciplinary robotics STEM curriculum based on thematic integration and task-oriented instruction. Journal of Science Education, 26(4), 305-331. https://doi.org/10.6173/CJSE.201812_26(4).0002 
Chen, Y., \& Chang, C. C. (2018). The impact of an integrated robotics STEM course with a sailboat topic on high school students' perceptions of integrative STEM, interest, and career orientation. EURASIA Journal of Mathematics, Science and Technology Education, 14(12), 1614.

Cheng, Y. Y., Liu, K. S., \& Chang, C. M. (2007). The effect of creative problem solving instruction on elementary schools science lessons. Journal of Science Education, 15(5), 565-591. https://doi.org/10. 6173/CJSE.2007.1505.04

Chien, Y. H., Chu, P. Y., \& Chien, E. J. (2017). STEAM-oriented maker curriculum. Secondary Education, 68(2), 12-28. https://doi.org/10.6249/SE.2017.68.2.02

Chou, Y. C. (2013). The Study of the Creativity in STEM PBL Activity-Take CaC2 for Example, Unpublished master's thesis, Institute of Vocational Education, National Pingtung University of Science and Technology, National Pingtung University of Science and Technology.

Druin, A. (2002). The role of children in the design of new technology. Behaviour \& Information Technology, 21(1), 1-25. https://doi.org/10.1080/01449290110108659

Ejiwale, J. A. (2013). Barriers to successful implementation of STEM education. Journal of Education and Learning, 7(2), 63-74. https://doi.org/10.11591/edulearn.v7i2.220

Govers, E., Major, S., \& Verburg, C. (2014). Project-based learning in visual arts and design: What makes it work?, Redeveloping a traditional arts and design degree into a 21 st century projectbased learning programme. https://akoaotearoa.ac.nz/research-register/list/project-based.

Henriksen, D. (2017). Creating STEAM with design thinking: Beyond STEM and arts integration. The STEAM Journal. https://doi.org/10.5642/steam.20170301.11

Isaksen, S. G., Dorval, K. B., \& Treffinger, D. J. (2000). Creative approaches to problem solving. Dubuque, IA: Kendall/Hunt.

Land, M. H. (2013). Full STEAM ahead: The benefits of integrating the arts into STEM. Procedia Computer Science, 20, 547-552. https://doi.org/10.1016/j.procs.2013.09.317

Liao, C. (2016). From interdisciplinary to trans-disciplinary: An arts-integrated approach to STEAM education. Art Education, 69(6), 44-49. https://doi.org/10.1080/00043125.2016.1224873

Lin, H.T., \& Wang M.R. (1994). Williams creativity assessment packet. Psychology.

James, H. R. (2016). Reinventing the STEAM engine for art design education. Art Education, 69(4), 4-7. https://doi.org/10.1080/00043125.2016.1176848

Kokotsaki, D., Menzies, V., \& Wiggins, A. (2016). Project-based learning: A review of the literature. Improving Schools, 19(3), 267-277. https://doi.org/10.1177/1365480216659733

Kuure, L., Halkola, E., Iivari, N., Kinnula, M., \& Molin-Juustila, T. (2010, November). Children imitate!: appreciating recycling in participatory design with children. Paper presented at the 11th Biennial Participatory Design. Sydney, Australia. https://doi.org/10.1145/1900441.1900460

Maryland State Board of Education (2012). Maryland STEM: Innovation today to meet tomorrow's global challenges. Maryland State department of education, Retrieved September 07, 2019, from http:// mdk12.msde.maryland.gov/instruction/curriculum/STEM/pdf/STEMBrochure2012.pdf.

Mao, L., Guo Y. Y., Chen, L.G., \& Lin H. T. (2000). Creativity research. Psychology.

Hawari, M. O. H. D., \& Ahmad Dasuki; MOHD NOOR, Azlin Iryani. (2020). Project based learning pedagogical design in STEAM Art education. Asian Journal of University Education, 16(3), 102-111. https://doi.org/10.24191/ajue.v16i3.11072

National Research Council. (2011). Successful K-12 STEM education: Identifying effective approaches in science, technology, engineering, and mathematics. National Academies Press. https://doi.org/10. $17226 / 13158$

Ni, H. L. (2012). Chinese paper-cutting techniques are used in innovative designs. Unpublished master's thesis, Ming Chi University of Technology Design Institute, New Taipei City.

Ozkan, G., \& Umdu Topsakal, U. (2021). Exploring the effectiveness of STEAM design processes on middle school students' creativity. International Journal of Technology and Design Education, 31, 95-116. https://doi.org/10.1007/s10798-019-09547-z

Oner, A. T., Nite, S. B., Capraro, R. M., \& Capraro, M. M. (2016). From STEM to STEAM: Students' beliefs about the use of their creativity. The STEAM Journal, 2(2), 6.

Ravitz, J. (2008). Project based learning as a catalyst in reforming high schools. Buck Institute for Education.

Salinger, G., \& Zuga, K. (2009). Background and history of the STEM movement. In the International Technology Education Association (Eds.), The Overlooked STEM Imperatives: Technology and Engineering-K12 Education (pp.4-9). Reston, VA: International Technology Education Association.

Sentance, S., Waite, J., Hodges, S., MacLeod, E., \& Yeomans, L. E. (2017, March). Creating Cool StuffPupils' experience of the BBC micro: bit. Paper presented at the 48th ACM technical symposium on computer science education: SIGCSE 2017. https://doi.org/10.1145/3017680.3017749 
Song, M. J. (2020). The application of digital fabrication technologies to the art and design curriculum in a teacher preparation program: A case study. International Journal Technology Design and Education, 30, 687-707. https://doi.org/10.1007/s10798-019-09524-6

Stein, M. I. (1967). Creativity and culture. In R. L. Moony \& T. A. Razik (Eds.), Explorations in creativity (pp. 109-119). Harper \& Row.

Sternberg, R. J., \& Lubart, T. I. (1995). Defying the crowd: Cultivating creativity in a culture of conformity. Free Press.

Sullivan, F. R., \& Heffernan, J. (2016). Robotic construction kits as computational manipulatives for learning in the STEM disciplines. Journal of Research on Technology in Education, 48(2), 105-128.

Wang Y. D. (2014). Auspicious paper-cut creative wall stickers are applied to the creation and research of interior decoration. Unpublished master's thesis, Department of Art and Design, National Dong Hwa University, Hualien County. https://hdl.handle.net/11296/76zn8s

Varotsis, G., \& Vasalou, A. (2019). Leading by example: Exploring the influence of design examples on children's creative ideation. International Journal of Human-Computer Studies, 122, 174-183.

Vernon, P. E. (1989). The nature-nurture problem in creativity. Plenum Publishing Corp.

Williams, F. E. (1972). Encouraging creative potential. Educational Technology Publications.

Yakman, G. (2008). STEAM education: An overview of creating a model of integrative education. Retrieved September, 07, 2019, from http://www.iteea.org/File.aspx?id=86752\&v=75ab076a.

Yang B.F. (2015).An action research on the development of school children's creativity through paper cutting course - a case research on the second grade students of the Elementary School, Master's Program in Industrial Design, Huafan University, New Taipei City. https://hdl.handle.net/11296/ch4386

Publisher's Note Springer Nature remains neutral with regard to jurisdictional claims in published maps and institutional affiliations. 